
J. Egypt. Soc. Parasitol. (JESP), 50(3), 2020: 712-718

(Online: 2090-2549)

\title{
OCCURRENCE AND SPECIES COMPOSITION OF THE DOMESTIC MITES IN SIX EGYPTIAN GOVERNORATES \\ By
}

\begin{abstract}
ASMAA M. AMMAR, ELHAM A. EL ZAYYAT, AMIRA E. KHAYYAL*, AND NOHA A. ELLEBOUDY ${ }^{1}$

Department of Medical Parasitology, Faculty of Medicine, Ain-Shams University, Cairo 11566, Egypt ('Correspondence: amira_elsaady12@yahoo.com)

Abstract

Domestic mites, the combined group of household-living storage mites and pyroglyphid housedust mites, belong to subclass Acari. Identifying mites to species level help to improve the management of their allergies as they produce species-specific allergens. Knowledge of the impact of the diverse and changing ecological conditions in the home environment is useful in developing strategies to avoid the development and growth of large populations of domestic allergic mites. This study identified domestic mite's species in six Egyptian Governorates. The dust samples were collected from the HDM allergic patients for identification and seasonal distribution. From 120 samples, seven species were identified: Dermatophagoides farinae (69.4\%), D. pteronyssinus (55.5\%), Tyrophagus spp. (38.8\%), Blomia tropicalis (30.5\%), Cheyletus spp. (13.8\%), Euroglyphus maynei (5.5\%), and Tarsonemus spp. (5.5\%). The highest positive samples were in Qalyobia Governorate (73.7\%) and lowest in Cairo Governorate (33.3\%). Highest number of mites was in spring and autumn seasons, and $D$. farinae was the commonest one.
\end{abstract}

Keywords: Egypt, Dermatophagoides, Tyrophagus, Blomia, and seasonal variation.

\section{Introduction}

House-dust mites are the major source of the allergens in house dust. They have adapted to living in or around human habitations such as houses and storage facilities for grain and hay (Johnston et al, 2018). They are members of the family Pyroglyphidae of which Dermatophagoides farinae (D. farin$a e$ ) and $D$. pteronyssinus were the most significant ones. The storage mites belonged to Astigmata families, often found in grains, hay, and straw (Colloff, 2009). Environmental factors as temperature, humidity, and ecology influenced mites' growth and prevalence (Casley et al, 2018).

Domestic mites (HDM) cause different allergic conditions as sneezing, runny nose, itchy, red or watery eyes, stuffy nose, itchy nose, itchy skin and mouth or throat as well as cough (Attia et al, 2019). The sensitizing and developing allergic symptoms are particularly in children and immuno-compromised (Soleimani-Ahmadi et al, 2017). The pyroglyphid mites account for $>90 \%$ of the mite population in doors (Saad et al, 2006). House dust mites and their complications were reported among man and domestic animals in many Egyptian Governorates such as Qalyobia (Morsy et al, 1994), Suez Canal Zone (El-Kady et al, 1995), Dakahlia (ElShazly et al, 2006), South Sinai (El-Kady et al, 1998), North Sinai (El-Sherbiny et al, 2010), Alexandria (Sadaka et al, 2000), Cairo (Kenawy et al, 2012), Menoufia (El Kersh et al, 2016), and Sohag (

This study aimed to determine the domestic mite species composition by using light and electron microscopy and to study their indoors seasonal variations in allergic patient's in six representative Egyptian Governorates (Cairo, Qalyobia, Menoufia, Dakahlia, Sharkia, and Menia).

\section{Materials and Methods}

Collection of house dust samples: A total of 120 dust samples were collected from 60 mites infested houses with patients suffered from allergic rhinitis, allergic dermatitis and/or asthma over the period from August 2018 to November 2019. Dust samples were collected seasonally in separate labelled bags. The studied population was asked to bring two dust samples from different areas of their houses using a vacuum cleaner. The second sample was considered as a replicate. Dust samples were collected from the bedrooms, mattresses, floor, bedding, living roo 
$\mathrm{ms}$, and kitchens. One square meter of each place was vacuumed for 2-3 min. Collected dust was kept inside a disposable plastic bag and carefully tied. Collected dust was stored at $4{ }^{\circ} \mathrm{C}$ to avoid mites escaping by decreasing their motility and transferred to the laboratory within $24 \mathrm{hr}$ in separate labelled bags.

Examination of dust samples: The samples were sieved through a stainless-steel mesh screen ( $6 \mathrm{~cm}$ diameter, $500 \mu \mathrm{m}$ pore size) to remove large particles and fibres, mites were extracted from sieved dust samples using Berlese funnels. Fifty grams of a sample of dust was placed on the stainless-steel sieve $20 \mathrm{~cm}$ diameter. The funnel was placed directly under a light bulb $(25 \mathrm{~V})$ fixed $7 \mathrm{~cm}$ abo ve the sieve containing dust for half an hour to be separated in a glass Petri-dish $(10 \mathrm{~cm})$ and then examined under a stereomicroscope $10 x \& 30 x$. Four samples of 1 gm each were examined for mites and counted per site and species. Each identified species was isolated in a separate glass Petri dish with the aid of a needle tip (Heikal, 2015).

Identification of mites: A-The temporary preparation method: For more accurate identification, isolated dust mites were mounted on glass slides in a drop of $70 \%$ ethanol, and examined directly under a research microscope (100x \& 400x) and identified adopting the standard keys (Colloff, 2009). B- SEM identifications: Mites were removed from the collected dust using a needle tip and transferred to Glutaraldehyde after that, they were dehydrated by washing for $15 \mathrm{~min}$ in a graded series of ethanol $(40 \%, 50 \%, 60 \%$, $70 \%, 80 \%, \& 90 \%)$ and absolute ethanol. The mites were then dried to a critical level, before being mounted and placed on platforms prepared with adhesive tape, coated with gold and examined through a The FEI ESEM Quanta 450 FEG 501 SEM using accelerating voltages of $15 \& 30 \mathrm{KV}$, at the National Research Centre, Dokki, Giza.

Statistical analysis: Data analysis was performed using the software SPSS version 20. Statistical presentation and analysis of the present study were conducted, using the me- an, standard deviation, and Kruskal-Wallis test.

\section{Results}

Morphology and classification: A mite has a tiny oval or globular body $(0.2-0.4 \mathrm{~mm})$, bilaterally symmetrical body, and covered with a tough translucent cuticle, white to light tan coloured. Cuticle striated, and long setae (hairs) to outer body margins and shorter setae on rest of body. Adult with four pairs of legs, each end with a pair of claws and mouth parts protruded anteriorly forming capitulum armed with chelicerae. Mite body consists of three main parts: gnathosoma carried mouthparts, propodosoma carried forelegs, and hysterosoma carried hind-legs and external adult sexual organs. Body and legs covered with many setae of various sizes, structures, and functions.

The dust mites were isolated from $72 / 120$ $(60 \%)$ samples from houses in different areas six governorates. Qalyobia showed the highest rate $(73.7 \%)$, and Cairo the lowest one $(33.3 \%)$. The recovered house dust mites were Dermatophagoides farinae, D. pteronyssinus and Euroglyphus maynei of family Pyroglyphidae (Wharton, 1976).

Storage mites were Tyrophagus putrescentiae of family Acaridae and Blomia tropicalis of family Echymyopodidae and Cheyletus spp. of family Cheyletidae and Tarsonemus spp. of family Tarsonemidae (Hughes 1976).

The majority of dust samples contained different mite species, but some samples showed only one mite type. D. farinae was predominant 50/72 (69.4\%) isolated from all samples, which accounted for $45.4 \%$ of the total mites. Other species as Cheyletus spp. and Tarsonemus spp. were sporadic isolated ( $<1 \%$ of total mites).

Mites' seasonal distribution from six governorates on years 2018/2019 showed significant difference in all collections $(p \leq 0.05)$. Pyroglyphidae species were the lowest in su mmer and the highest in spring and autumn. Species of families Echymyopodidae, Acaridae, Cheyletidae \& Tarsonemidae were statistical highest in spring, but rare in winter. 
The details were given in tables $(1,2, \& 3)$ and figures $(1,2,3,4, \& 5)$.

Table 1: Domestic mites in collected dust from six Governorates in Egypt

\begin{tabular}{|l|c|c|}
\hline Governorate & Number of samples & Number of positive domestic mite samples (\%) \\
\hline Cairo & 12 & $4(33.3 \%)$ \\
\hline Menia & 12 & $6(50 \%)$ \\
\hline Menoufia & 26 & $16(61.5 \%)$ \\
\hline Qalyubia & 30 & $22(73.7 \%)$ \\
\hline Sharkia & 22 & $14(63.6 \%)$ \\
\hline Dakahlia & 18 & $10(55.5 \%)$ \\
\hline Total & 120 & $72(60 \%)$ \\
\hline
\end{tabular}

Qalyubia showed highest rate (73.7\%), and Cairo lowest (33.3\%)

Table 2 Identification and population density in one gram of dust samples over four / year:

\begin{tabular}{|l|c|c|}
\hline \multicolumn{1}{|c|}{ Type of mite } & Total No. of mites & Species composition (\%) \\
\hline Pyroglyphidae: Dermatophagoides farina & 3056 & $45.4 \%$ \\
: D. pteronyssinus & 1312 & $19.5 \%$ \\
: E. maynei & 142 & $2.1 \%$ \\
\hline Echymyopodidae: Blomia tropicalis & 836 & $12.42 \%$ \\
\hline Acaridae: Tyrophagus putrescentiae & 1336 & $19.84 \%$ \\
\hline Cheyletidae: Cheyletus malaccensis & 40 & $0.6 \%$ \\
\hline Tarsonemidae: Tarsonemus spp. & 10 & $0.14 \%$ \\
\hline Total & 6732 & $100 \%$ \\
\hline
\end{tabular}

Predominant species $D$. farinae and least one Tarsonemus spp.

Table 3: Population density of dust mites in one-gram dust collected from houses at 2018/2019-year seasons:

\begin{tabular}{|l|l|l|l|l|l|l|}
\hline Type of mite & Winter & Spring & Summer & Autumn & H value & P value \\
\hline D. farina & $45 \pm 4.4$ & $82.6 \pm 6.7$ & $27 \pm 3.6$ & $76.7 \pm 7.5$ & 16.6314 & $0.008^{*}$ \\
D. pteronyssinus & $25.6 \pm 6.8$ & $49 \pm 4.9$ & $14.6 \pm 3.8$ & $42 \pm 5.9$ & 17.8571 & $0.0047^{*}$ \\
E. maynei & $7.3 \pm 2.5$ & $9.3 \pm 2.5$ & $4 \pm 3.6$ & $8.6 \pm 4.2$ & 15.7886 & $0.0125^{*}$ \\
\hline Blomia tropicalis & $6 \pm 6.5$ & $33.4 \pm 6.6$ & $28.2 \pm 5.8$ & $20 \pm 7.7$ & 17.8571 & $0.0047^{*}$ \\
\hline Tyrophagus putrescentiae & $15.8 \pm 5.3$ & $54.6 \pm 5.8$ & $36.6 \pm 6.5$ & $33 \pm 11.5$ & 17.7171 & $0.005^{*}$ \\
\hline Cheyletus malaccensis & $0.75 \pm 0.95$ & $8.2 \pm 1.25$ & $5.5 \pm 2.1$ & $3.5 \pm 1.3$ & 17.3314 & $0.006^{*}$ \\
\hline Tarsonemus spp. & $00 \pm 00$ & $2.25 \pm 1.3$ & $1.0 \pm 0.8$ & $0.5 \pm 0.58$ & 13.3743 & $.0038^{*}$ \\
\hline
\end{tabular}

All data represented as Median and SD. Kruskal-Wallis Test was used. $* p \leq 0.05$ was significant.

\section{Discussion}

In the present study, $72(60 \%)$ of collected dust samples were positive for domestic mites. Seven species of five families were isolated from the house dust collected from 60 houses of mites' allergic patients from in the six governorates. These mites in descending order of abundance were Dermatophagoides farinae (45.4\%), Tyrophagus putrescentiae (19.8\%), D. pteronyssinus (19.5\%), Blomia tropicalis (12.42\%), Euroglyphus maynei (2.1\%), Cheyletus spp. (0.6\%) and Tarsonemus spp. (0.14\%).

These mites species were reported from some Egyptian Governorates such as Gharbia (Gamal-Eddin et al, 1982; 1985), Menia (Gamal-Eddin and Shoker 1989), Sharkia (Gamal-Eddin and El-Besheir, 1990), South Sinai (El-Kady et al, 1998), Cairo (Koraiem and Fahmy, 1999; Yassin, 2011; Kenawy et al, 2012), Alexandria (Sadaka et al, 2000), Dakahlia (El-Shazly et al, 2006) and North Sinai (El-Sherbiny et al, 2010). Also, Saleh et al. (2013) in a hospital recovered mites from allergic patients and nursing staff and considered mites allergy occupational safety or source of work-related allergens.

In the present study, D. farinae was the predominant species in all samples examined. This agreed with Kenawy et al. (2012) who reported that in Cairo Governorate, $D$. farinae $(80 \%)$ was the dominant one. Also, Hossny et al. (2014) found that D. pteronyssinus and $D$. farinae were the most prevalent species among mites' allergic children. Besides, Heikal (2015) found that in Menoufia Governorate, D. farinae mites (5276) represented $66.1 \%$ of total collected mites

Abroad, Warner et al. (1999) in Sweden reported that $D$. farinae numbers collected from three climatic regions homes were more than that of $D$. pteronyssinus and their density increased in homes with high humidity and was higher in bungalows than in the flats. Sopelete et al. (2000) and Nascimento et al. (2016) in Brazil reported a higher pre- 
valence of $D$. farinae than $D$. pteronyssinus. They added that humid indoor conditions and availability of blankets and clothes encourage a favourable climate for HD mites' growth during humid seasons. Milián and Díaz (2004) reported that D. pteronyssinus was found primarily in high relative humidity $(>45 \%)$ and warm temperatures around the world, from 18 to $30^{\circ} \mathrm{C}$, but $D$. farinae was mainly found in dry continental climates, rare in coastal climates such as the Mediterranean. Sharma et al. (2011) in India reported that mites in the dust samples varied from place to another due to the difference in structure, houses' age, individual status, type of furniture and difference in microclimate conditions that lead to the increased accumulation of mites in home dust. Soleimani-Ahmadi et al. (2017) in Iran reported that D. pteronyssinus $(31.06 \%)$, D. evansi (23.49\%), D. farinae (17.75\%), Ornithonyssus bacoti (19.45\%), and Cheyletus malaccensis $(8.25 \%)$, were the main allergenic dust mite species $D$. pteronyssinus and $D$. farinae co-inhabited and collected from all kindergartens. Wilson and Platts-Mills (2018) in USA stated that dust mite allergy contributed to asthma worldwide, and long-term avoidance could be effective for preventing sensitization and minimizing development and severity of respiratory disease. Miller (2019) in USA reported that the major allergenic dust mites $D$. pteronyssinus, $D$. farinae, Euroglyphus maynei, and B. tropicalis were eight-legged members of class Arachnid.

Thus, in the current study the high frequency of $D$. farinae was due to a moderately hot climate in Egypt and low frequency of $D$. pteronyssinus was attributed to unfavourable environmental conditions of relatively low humidity.

In the present study, seasonal variation affected mite populations; Pyroglyphidae mites were more abundant during the spring and early autumn, and the least Pyroglyphidae mites' number was in summer season. As to mites of families Echymyopodidae, Acarid- ae, Cheyletidae, and Tarsonemidae the highest numbers were during spring season and the least was in the winter. This agreed with Heikal (2015) in Menoufia Governorate, where the summer recorded the least Pyroglyphidae mite number, but spring and autu$\mathrm{mn}$ yielded the highest mite numbers. Also, Ahmed et al. (2020) in Menia Governorate reported the highest storage mite density in spring and the lowest was in winter.

Abroad, Feng et al, (2009) in china reported that the worldwide seasonal variation of domestic mite species showed diverse patterns, based on varying temperature, humidity, and food availability. Nascimento et al. (2016) in Brazil found that the coldest seasons yielded largest dust mite populations, but summer showed least abundance.

Shafique et al. (2018) in Pakistan reported that $D$. farinae and D. pteronyssinus were significantly higher in rainy summer season Winter et al. (2018) in Germany, stated that the global change processes affect seasonal dynamics of salt marshes and thereby their plant and animal communities. But, these changes have been little investigated for microarthropod communities.

\section{Conclusion}

Seven known species of domestic mites were recovered from the six surveyed governorates. These were in a descending order of abundance; Dermatophagoides farinae, D. pteronyssinus, Tyrophagus spp., Blomia tropicalis, Cheyletus spp., Euroglyphus maynei, and Tarsonemus spp. The D. farinae was the commonest one in the studied areas. The mite allergens indoor was high in cool months with heavy clothes and blankets.

No doubt, exposure of the furniture to sun and careful cleaning of indoors and avoiding pet animals is a must. Clinical pictures from mite sensitization and exposure include rhinitis, sinusitis, conjunctivitis, asthma, and atopic dermatitis. However, these allergic symptoms can also occur from the ingestion of cross-reacting invertebrates, such as shrimp or snail, or from the accidental ingestion of mite-contaminated foods. 


\section{Acknowledgements}

The authors are grateful to Dr. Matthew Colloff, Fener School of Environment and Society, Australian National University, for his kind support in verifying the present mites' species identification.

Ethics approval: The study followed the regulations of the Egyptian Ministry of Higher Education and obtained the required approval of the ethical committee of the Faculty of Medicine Ain Shams University.

Conflicts of interest: The authors neither have conflict of interest nor received fund.

Authors' contributions: All authors equally contributed in the field and laboratory activities as well as manuscript revision and approval.

\section{References}

Ahmed, NS, Ahmed, AM, 2020: Ornithonyssus sylviarum (Acari: Gamasida: Macronyssidae): A cause of pruritic dermatitis for poultry farm workers in Sohag Governorate, Egypt. J. Egypt. Soc. Parasitol. 50:599-604

Ahmed, AK, Kamal, AM, Mowafy, NME, Hassan, EE, 2020: Storage mite infestation of drystored food products and its relation to human intestinal acariasis in the city of Minia, Egypt. J. Med. Entomol. 57, 2:329-35.

Atta, AH, Amer, RM, Mesbah, AE, Khater, MW, 2019: Sublingual versus subcutaneous immuno-therapy as regards efficacy and safety in respiratory allergic patients. Egypt. J. Immunol. 26, 2:65-78.

Casley, LS, Godec, T, Logan, JG, Pearce, JC, Smith, HM, et al, 2018: How clean is your house? A study of house dust mites, allergens and other contents of dust samples collected from households. Int. J. Environ. Hlth. Res. 28, 4:34157.

Colloff, MJ, 2009: Physiology and Internal Anatomy, In: Dust Mites. $1^{\text {st }}$ ed. Dordrecht, The Netherlands and CSIRO, Collingwood, Australia: Springer.

El Kady, GA, Makled, KM, Morsy TA, Morsy, ZS, 1998: Rodents, their seasonal activity, ecto- and blood-parasites in Saint Catherine Area, South Sinai Governorate, Egypt. J. Egypt. Soc. Parasitol. 28, 3:815-26.

El Kady, GA, Shoukry, A, EI Said, AM, Raghab, DA, Habib, KM, et al, 1995: Mites (Acari) infesting commensal rats in Suez Canal Zo- ne, Egypt. J. Egypt. Soc. Parasitol. 25, 2: 417-25. El Kersh, WM, El Sobky, MMK, Harbah, N M, Heikl, HM, Abou Galalah, DIM, 2019: Morphological identification of house dust mite species in Menoufia Governorate and their antigen effect in immunoglobulin $\mathrm{E}$ response in allergic patients. Menoufia Med. J. 32:88-96.

El-Shazly, AM, El-Beshbishi, SN, Azab, MS, El-Nahas, HA, Soliman, ME, et al, 2006: Present situation of house dust mites in Dakahlia Governorate, Egypt. J. Egypt. Soc. Parasitol. 36, 1: 113-26.

El-Sherbiny, GT, El-Sherbini, ET, Saled, NM, Haridy, FM, Morsy, AT, 2010: A study on the prevalence of house dust mites in Al-Arish city, North Sinai Governorate, Egypt. J. Egypt. Soc. Parasitol. 40, 1:57-70.

Feng, M, Sun, W, Cheng, X, 2009: Seasonal dynamics and distribution of house dust mites in China. Bio-Sci. Trends 3, 6:210-5.

Gamal-Eddin, FM, Shoker, NI, 1989: The present status and ecology of house dust mites in El Minia Governorate (Upper Egypt), as basis for future studies on environment pollution with house dust mite allergens or on vaccination with specific mite antigens. J. Egypt. Soc. Parasitol. 19:332-41.

Gamal-Eddin, FM, El-Besheir, Z, 1990: Surveillance and ecology of house dust mites in some rural and urban areas of Sharquiya Governorate (South-Eastern of the Nile Delta) as guidelines for preparation of the diagnostic antigens and vaccines in addition to avoidance measures. J. Egypt. Soc. Parasitol. 20: 28-43.

Gamal-Eddin, FM, Tayel, SE, Abou Sinaa, F M, Shehata, KK, 1982: Present status and ecology of house dust mites in Egypt as approaches to environmental control of mites and preparation of specific diagnostic antigen before resort to any desensitizing vaccine. J. Egypt. Soc. Parasitol. 12:253-82.

Gamal-Eddin, FM, Tayel, S.E, Aboul Atta, A M, Abou-Sinna, FM, 1985: House dust mite sensitive asthma: preliminary study on its incidence and seasonal prevalence under the Egyptian environmental conditions. J. Egypt. Soc. Parasitol. 15: 71-95.

Heikal, HM, 2015: Studies on the occurrence, identification and control of house dust mites at rural houses of Shebin El-Kom locality, Egypt. Pak. J. Biol. Sci. 18, 4:179-84.

Hossny, E, El-Sayed, S, Abdul-Rahman, N, 2014: Sensitivity to five types of house dust mi- 
te in a group of allergic Egyptian children. Pediatr. Allergy Immunol. Pulmonol. 27, 3:133-7. Hughes, AM, 1976: The Mites of Stored Food and Houses. $2^{\text {nd }}$ Edition. Her Majesty's Stationery Office, London, England.

Johnston, JD, Barney, TP, Crandall, JH, Brown, MA, Westover, TR, et al, 2018: Prevalence of house dust mite allergens in low-income homes with evaporative coolers in a semiarid climate. Arch. Environ. Occup. Hlth. 73, 1:38-41.

Kenawy, MA, Awad, AA, El-Shafei, AM, Helmi, N, Abdel-Hamid, YM, et al, 2012: House dust mites associated with the asthmatic patients in some houses of Cairo, Egypt. Acad. J. Biol. Sci., Med. Entomol. Parasitol. 4, 1:1-5.

Koraiem, MK, Fahmy, IA, 1999: Studies on house dust mites in Great Cairo, Egypt. J. Egypt. Soc. Parasitol. 29, 1:131-8.

Milián, E, Díaz, AM, 2004: Allergy to house dust mites and asthma. P R Health Sci. J. 23, 1: 47-57.

Miller, J, 2019: The role of dust mites in allergy. Clin. Rev. Allergy Immunol. 57, 3:312-29.

Morsy, TA, Zohdi, HW, Abdalla, KF, El Fakahani, AF, Ibrahim, AA, et al, 1994: Isolation of three species of mites from house dust of atopic dermatitis patients in Qualyobia Governoraate, Egypt. J. Egypt. Soc. Parasitol. 24, 2:323-32. Nascimento, JM, Reis-Avila, G, Dutra, MS, Silva, DE, Castro, LCD, et al, 2017: Seasonal and environmental variations in community structure of house dust mites (Acari) in sub-tropical southern Brazil. Int. J. Acarol. 43, 1:86-90.

Saad, EZ, Hussien, R, Saher, F, Ahmed, Z, 2006: Acaricidal activities of some essential oils and their monoterpenoidal constituents against house dust mite, Dermatophagoides pteronyssinus (Acari: Pyroglyphidae). J. Zhejiang Univ. Sci. B 7, 12: 957-62.

Sadaka, HA, Allam, SR, Rezk, HA, Aboel-Nazar, SY, Shola, AY, 2000: Isolation of dust mites from houses of Egyptian allergic patients and induction of experimental sensitivity by Dermatophagoides pteronyssinus. J. Egypt. Soc. Parasitol. 30:263-76.

Shafique, RH, Akhter, S, Abbas, S, Ismail, M, 2018: Sensitivity to house dust mite allergens and prevalence of allergy-causing house dust mite species in Pothwar, Pakistan. Exp. Appl. Acarol. 74, 4:415-26.

Sharma, D, Dutta, BK, Singh, AB, 2011: Dust mites population in indoor houses of suspected allergic patients of South Assam, India. Int. Sch. Res. Not. 7:2011. doi: 10.5402/2011/576849.

Soleimani-Ahmadi, M, Zare, M, Abtahi, SM, Khazeni, A, 2017: Species identification and prevalence of house dust mites as respiratory allergen in kindergartens of the Bandar Abbas City. Iran. J. Aller. Asthma Immunol. 16, 2:133-9.

Sopelete, MC, Silva, DA, Arruda, LK, Chapman, MD, Taketomi, EA, 2000: Dermatophagoides farinae (Der f 1) and Dermatophagoides pteronyssinus (Der p 1) allergen exposure among subjects living in Uberlandia, Brazil. Int. Arch. Aller. Immunol. 122, 4:257-63.

Warner, A, Boström, S, Möller, C, Kjellman, NI, Warner, A, 1999: Mite fauna in the home and sensitivity to house-dust and storage mites. Allergy 54, 7:681-90.

Wharton, GW, 1976: House dust mites. J. Med. Entomol., 12:577-621.

Wilson, JM, Platts-Mills, TAE, 2018: Home environmental interventions for house dust mite. J. Allergy Clin. Immunol. Pract. 6(1):1-7.

Winter, M, Haynert, K, Scheu, S, Maraun, K. 2018: Seasonal dynamics and changing sea level as determinants of the community and trophic structure of oribatid mites in a salt marsh of the Wadden Sea. LoS One 13, 11:e0207141.

Yassin, MK, 2011: Allergenic Dermatophagoides mites causing asthma among school children at Ain Shams District, Cairo, Egypt. J. Egypt. Soc. Parasitol. 41:47-54.

\section{Explanation of figures}

P.1: Domestic mites in house dust (adults) showed a- Tarsonemidae spp female with modified long legs IV with 2 apical setae without claw (400x). b \& c- Tyrophagus putrescentiae with dorsal transverse groove (400x). (d) Blomia tropicalis, globular shape mite with long dorsal setae (100x) \& e- Pyroglyphidae with finger- print striations pattern.

Fig 1: SEM images of Tyrophagus putrescentiae adult dorsal view highlighting idiosoma with a smooth cuticle. Idiosomal setae: internal and external scapular (sci \& sce, respectively), dorsal $(1,2,3, \& 4)$ with interior \& exterior vertical setae (vi \& ve). Idiosomal dorsal setae (1 \& 4) short and vi \& ve at anterior body end on propodosoma to chelicerae tip, with ve unequal to vi). Solenidion(s), arrow showed hollow, blunttipped structures.

Fig 2: SEM images of $D$. farinae female dorsal view showed idiosoma with a transverse striation in anterior half and convex or oblique striations in posterior one. Idiosomal setae, sce much longer than sci without vertical setae. Tarsi I \& II with large apical spine, and solenidia (S) on tarsus I at distal end of segment.

Fig 3: SEM images of Euroglyphus maynei female ventral view showed coarse body striations, vulva \& arched epigynum with lateral margin curved (arrow), $\mathrm{P}=$ pulvillus.

Fig 4: SEM images showed Cheyletus spp. gnathosoma with enlarged palps with an apical claw.

Fig 5: Seasonal variation among dust mite population in one-gram dust. All data represented as Median 

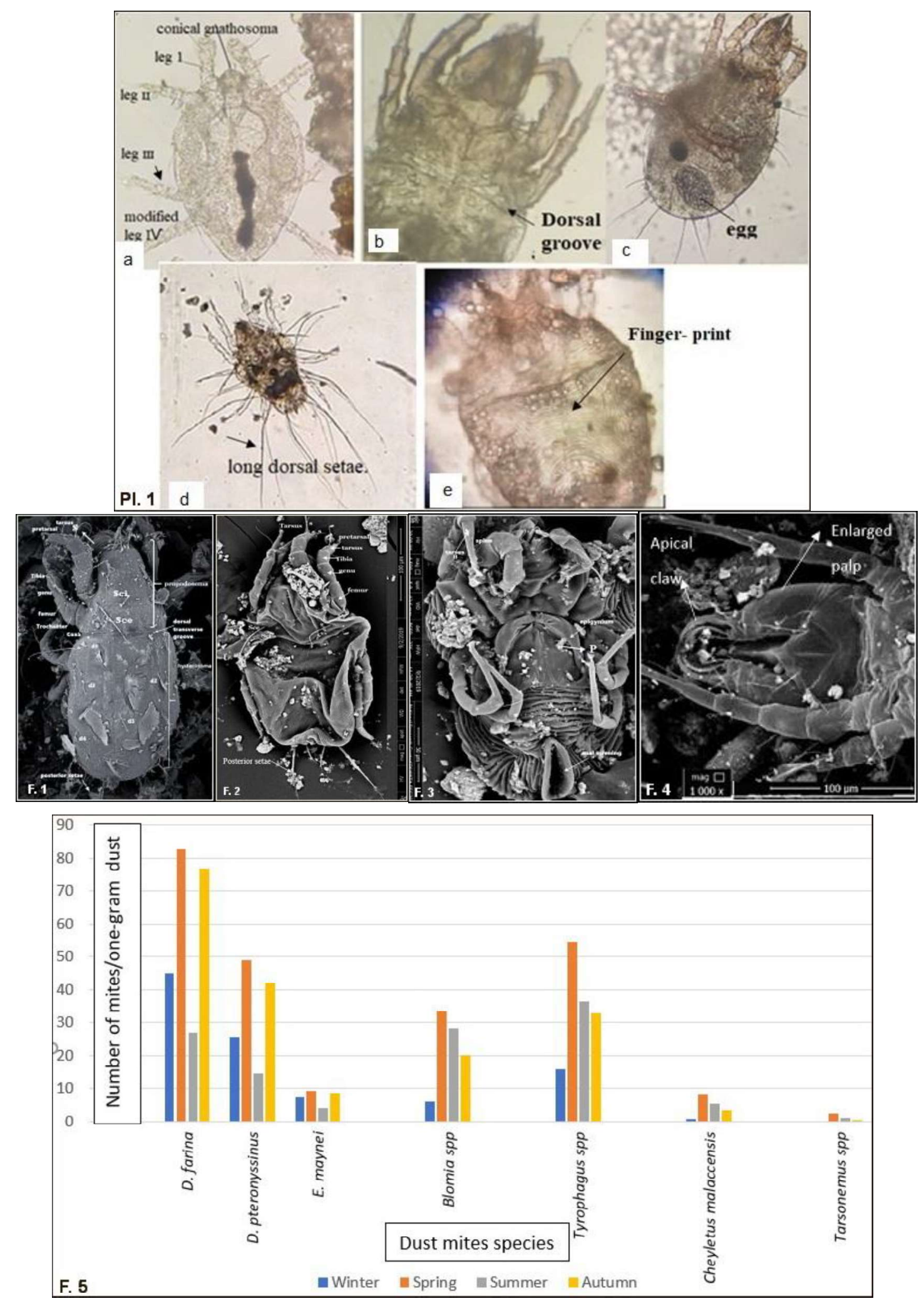